\title{
Temporal Patterns of Sporulation Potential of Phomopsis viticola on Infected Grape Shoots, Canes, and Rachises
}

\author{
D. J. Anco, L. V. Madden, and M. A. Ellis, The Ohio State University, Department of Plant Pathology, Ohio Agricultural Research and \\ Development Center, Wooster 44691
}

\begin{abstract}
Anco, D. J., Madden, L. V., and Ellis, M. A. 2012. Temporal patterns of sporulation potential of Phomopsis viticola on infected grape shoots, canes, and rachises. Plant Dis. 96:1297-1302.

Phomopsis cane and leaf spot on Vitis spp. (grape) is currently understood to be monocyclic, with primary inoculum only being produced early in the growing season. However, of the few published studies pertaining to sporulation of Phomopsis viticola, none specifically examined rachises, and none were designed to determine when infected tissues become capable of sporulation. The objective of these studies was to determine when grape shoots, canes, and rachises infected with $P$. viticola develop the capacity to sporulate, and to determine the time period during which those tissues remain capable of sporulation. Starting in 2009 and 2010, infected first-year shoots and rachises were collected biweekly throughout the growing season, into the dormant season, and into the following growing season. Tissues were collected from 'Catawba,' 'Concord,' and 'Reliance' vineyards.

Samples were observed for sporulation after $48 \mathrm{~h}$ of incubation in a moist chamber at $23^{\circ} \mathrm{C}$; the magnitude of the conidia production under these optimal conditions was considered the sporulation potential. For infections that occurred in 2009 and 2010, the production of conidia was not observed until after harvest. In the year following infection, sporulation potential was found from about bud break until shortly after the end of bloom. There was a generally consistent temporal pattern to relative sporulation potential across sampled vineyards, years, and grape tissues (rachises and canes), described by a modified $\beta$ model, with peak sporulation potential occurring around 16 May. These results confirmed that Phomopsis cane and leaf spot is a monocyclic disease and support control recommendations for use of fungicides in spring.
\end{abstract}

Despite fairly extensive fungicide programs, the incidence of Phomopsis cane and leaf spot (PCLS) appears to be increasing in many Ohio vineyards. This disease, caused by Phomopsis viticola (Sacc.) Sacc., occurs on Vitis spp. worldwide but becomes most economically important in temperate regions (9). Under favorable conditions, PCLS has been reported to reduce yields by up to $30 \%$ $(5,8)$. Although PCLS is capable of affecting all aboveground tissues of grape plants during some stage in their development, it has its greatest impact on yield when affecting fruit and rachises, which remain susceptible throughout the growing season (7).

PCLS is currently considered to be a monocyclic disease, and it is generally believed that infected tissue does not become capable of sporulation until the year following its infection. However, of the few published studies pertaining to sporulation of $P$. viticola $(4,11,14)$, none examined rachises, and none were designed to determine when infected tissues become capable of sporulation. This is an important part of the disease cycle of PCLS. The degree of necrosis (dead tissue) that develops on infected rachises makes them appear to be capable of supporting sporulation later in the growing season in which they were infected. If infected tissues become capable of sporulation during the same growing season in which they were infected, our understanding and management of PCLS would need to change to reflect this polycyclic nature of the disease and the production of secondary inoculum. Erincik et al. (7) demonstrated that fruit remain susceptible to infection throughout the growing season. If inoculum was produced during the later part of the season, fungicide protection of fruit would probably be required until harvest.

Furthermore, previously published reports were not designed to determine the duration that infected tissues remain capable of

Corresponding author: M. A. Ellis, E-mail: ellis.7@ osu.edu

Accepted for publication 20 March 2012.

http://dx.doi.org/10.1094/PDIS-09-11-0806-RE

(C) 2012 The American Phytopathological Society sporulation. This is another important part of the epidemiology of PCLS. If the duration that infected tissues remain capable of sporulation is different than our current understanding (i.e., from bud break until bloom), recommendations for chemical control of this disease would have to be updated accordingly. The objective of these studies was to determine when grape shoots, canes, and rachises infected with $P$. viticola develop the potential to sporulate and to determine the time period during which those tissues remain capable of sporulation.

\section{Materials and Methods}

Site selection. 'Catawba', 'Concord', and 'Reliance' vineyards used in these studies were located at Snyder Farm (N 40 45.84', W $\left.81^{\circ} 54.67^{\prime}\right)$ at the Ohio Agricultural Research and Development Center, Wooster. Vines were $2.1 \mathrm{~m}$ apart and rows were $3 \mathrm{~m}$ apart. One-year-old canes in each of the three vineyards were trained in position according to an umbrella Kniffin system. For each year following the initiation of this study, remaining 1-year-old infected canes were spur pruned and, when present, rachises were allowed to remain in the canopy. These vineyards had high levels of naturally occurring PCLS infections. In order to ensure ample infected tissues for other experiments not described here, the Catawba vineyard was inoculated with $P$. viticola wild-type strain $\mathrm{OH}-22$ at $10^{7}$ $\alpha$-conidia $\mathrm{ml}^{-1}$ by spraying young shoots and inflorescences until runoff. A handheld, 11-liter Challenger VI sprayer (Spartanburg Steel Products, Inc., Spartanburg, SC) was used to deliver inoculum. In 2009 and 2010, shoots between Eichhorn-Lorenz stage (EL) 09 and 12 were inoculated on 8 and 11 May, respectively, and inflorescences (EL-27) were inoculated on 30 and 11 June, respectively (6). After each inoculation, overhead irrigation was utilized to supplement natural rainfall to ensure sufficient wetness duration to produce an infection event with at least low predicted infection (data not shown; 15). For each inoculation, $\alpha$-conidia were produced by transferring $1.25-\mathrm{cm}^{3}$ potato dextrose agar (PDA) plugs containing actively growing hyphal tips of OH-22 onto each of 200 PDA plates. Plates were incubated under continual lighting $(12 \mu \mathrm{E}$ $\mathrm{m}^{-2} \mathrm{~s}^{-1}$ ) at $23^{\circ} \mathrm{C}$ for 14 days. The $\alpha$-conidia were collected by rinsing each plate with approximately $10 \mathrm{ml}$ of deionized water, and 
the resulting suspension was diluted to $10^{7}$ with deionized water and verified using a hemacytometer. Under these incubation conditions, $\mathrm{OH}-22$ did not produce $\beta$-conidia on PDA (unpublished).

Sample collection and incubation. Sampling began shortly after the development of visible symptoms (bluish-black lesions) of PCLS on shoots and rachises. Five infected first-year (produced and infected during the same growing season) shoots and rachises were indiscriminately collected biweekly from each vineyard. Sampling was continued through the growing and dormant seasons (except where specified for rachises) and continued into the growing season of the following year (Figs. 1 and 2). Sampling ceased when three consecutive sampling dates yielded no observed sporulation in the laboratory using the assay for sporulation potential described below.

Shoots (which became canes after the formation of periderm near the end of the growing season) produced and infected during the 2009 growing season were sampled from 28 July 2009 to 27 September 2010. Shoots (canes) produced and infected during the 2010 season were sampled from 26 May 2010 to 16 August 2011. Sampling of rachises produced and infected during the 2009 and 2010 growing seasons was conducted from 29 July 2009 to 6 Octo- ber 2010 and from 15 June 2010 to 16 August 2011, respectively. In order to leave enough rachises in the canopy to be sampled the following spring after vines would break dormancy, sampling of rachises was discontinued after 2 December 2009 and began again on 5 April 2010. Sampling of Catawba and Concord rachises produced and infected in 2010 ceased after 4 January 2011 and began again on 30 March 2011; Reliance rachises were not sampled after 21 October 2010 until 30 March 2011. Canes were sampled throughout the dormant season. In 2010 and 2011, available Reliance rachises were depleted on 17 March and 26 April, respectively; and, in 2011, available Concord rachises were depleted on 5 July.

After sampling, tissues were surface disinfested by soaking for 5 $\mathrm{s}$ in $70 \%$ ethanol and then $1 \mathrm{~min}$ in $0.5 \%$ sodium hypochlorite, and then rinsed under deionized water for $2 \mathrm{~min}$. Surface-disinfested tissues were placed in moist chambers $(22$ by 22 by $10 \mathrm{~cm}, 4.5-$ liter plastic containers) with approximately 1 liter of deionized water to induce sporulation. Metal screens were bent and placed in the bottom of the chambers to hold samples above the deionized water and below the plastic top. When sealed with $0.0508-\mathrm{mm}$ (2mil) clear polyethylene, dew point was reached within the cham-
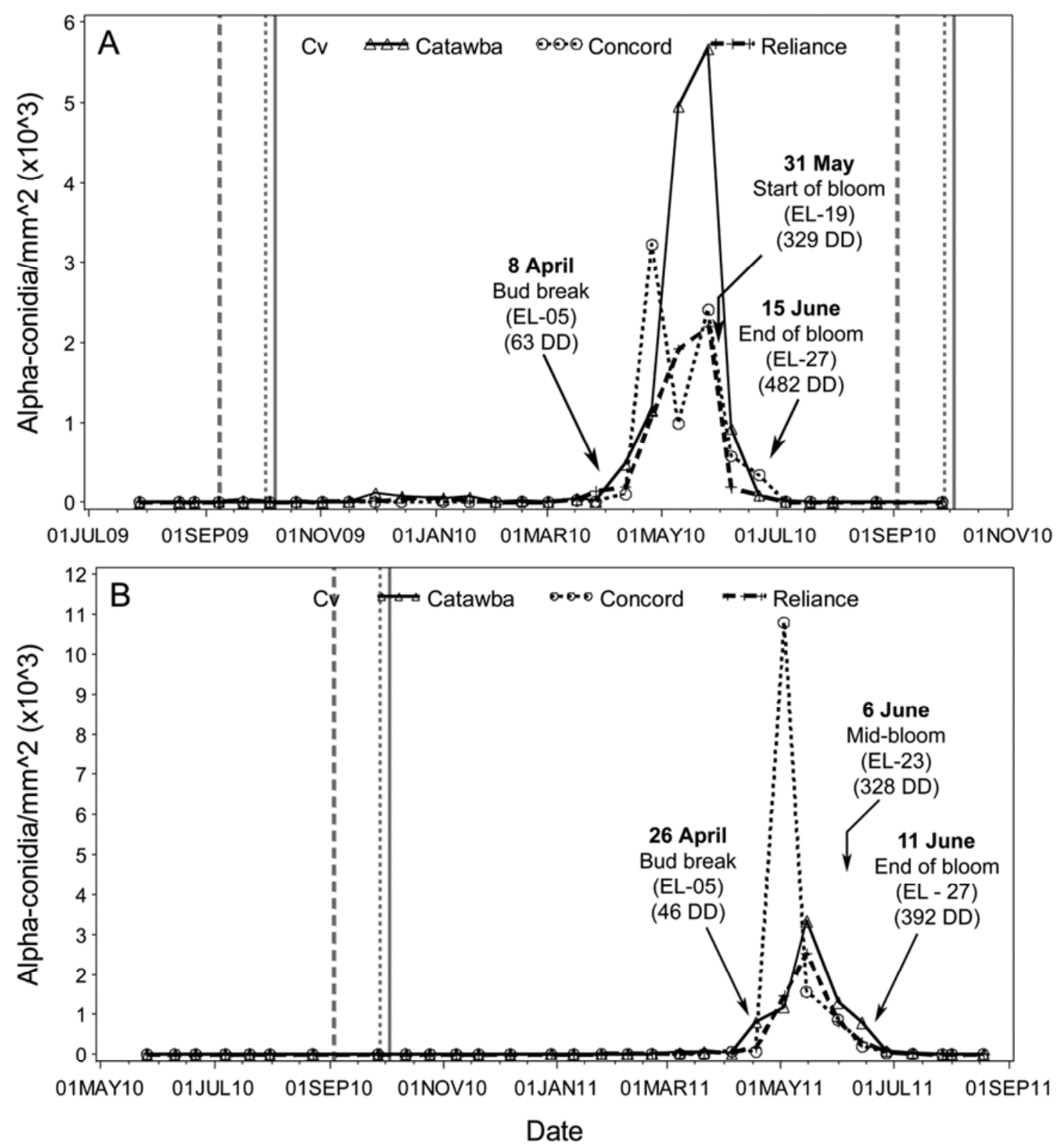

Fig. 1. Sporulation potential of Phomopsis viticola on grape shoots and canes infected in A, 2009 and B, 2010. Reference lines are approximate harvest dates of the respective cultivars. $\mathrm{EL}=$ Eichhorn-Lorenz growth stage and $\mathrm{DD}=$ degree-days (base $10^{\circ} \mathrm{C}$ ) since $1 \mathrm{April}$. 
bers. This resulted in relative humidity at $100 \%$ and, thus, maintained a layer of free water on the samples. The transparent polyethylene allowed light to penetrate. Moist chambers were randomly arranged in the center of a growth chamber at $23^{\circ} \mathrm{C}$ and maintained under continual fluorescent lighting with a photosynthetically active radiation output of $12 \mu \mathrm{E} \mathrm{m}^{-2} \mathrm{~s}^{-1}$ (model LQSQM; Apogee Quantum Meter, Logan, UT). Moist chambers were removed from the growth chamber after $48 \mathrm{~h}$, and sporulation on each sample was quantified. Temperature and wetness duration were verified within moist chambers in 5-min intervals with a WatchDog logger (model 130; Spectrum Technologies, Inc., Plainfield, IL; data not shown).

The sporulation on infected tissues at a given time in the laboratory assay described in the previous paragraph represents the capacity of $P$. viticola to sporulate if exposed to favorable environmental conditions, regardless of actual environmental conditions in the field. The magnitude of this spore production is labeled the sporulation potential, using terminology that has been used for the same phenomenon in other systems, including Fusicladium carpophilum (20), rice blast (10), and Botrytis cinerea (22). Thus, the laboratory-assay results were a measure of the sporulation potential of $P$. viticola on those tissues in the field at that time, because environmental conditions used to induce sporulation were optimal compared with those in the field.

Quantification of sporulation potential. Samples (shoots, canes, and rachises) were individually vortexed in $20 \mathrm{ml}$ of deionized water in 25-by-150-mm test tubes for $10 \mathrm{~s}$ using a Vortex Genie 2 (Fisher Scientific, Pittsburg) set at vortex speed 5. Sporulation on each sample was quantified by averaging six hemacytometer readings (providing a lower conidial concentration detection limit of approximately $1.67 \times 10^{3}$ conidia $/ \mathrm{ml}$ ), from which the number of conidia per $20-\mathrm{ml}$ suspension and per squaremillimeter sample surface area was calculated. Sample surface area was calculated assuming a surface area $(S)$ given by the sides of a cylinder, in which $S=2 \times \pi \times r \times h$, where $r$ is the radius and $h$ is the length of the samples. Surface area was separately calculated for each section (e.g., internode, pedicel, and peduncle) of different radii and summed to yield total estimated sample surface area. $P$. viticola $\alpha$-conidia were identified by morphology and colony characteristics when wash suspensions were occasionally spread on PDA amended with streptomycin sulfate at $0.05 \mathrm{~g} \mathrm{liter}^{-1}$. Plates were incubated as described previously. This process also verified
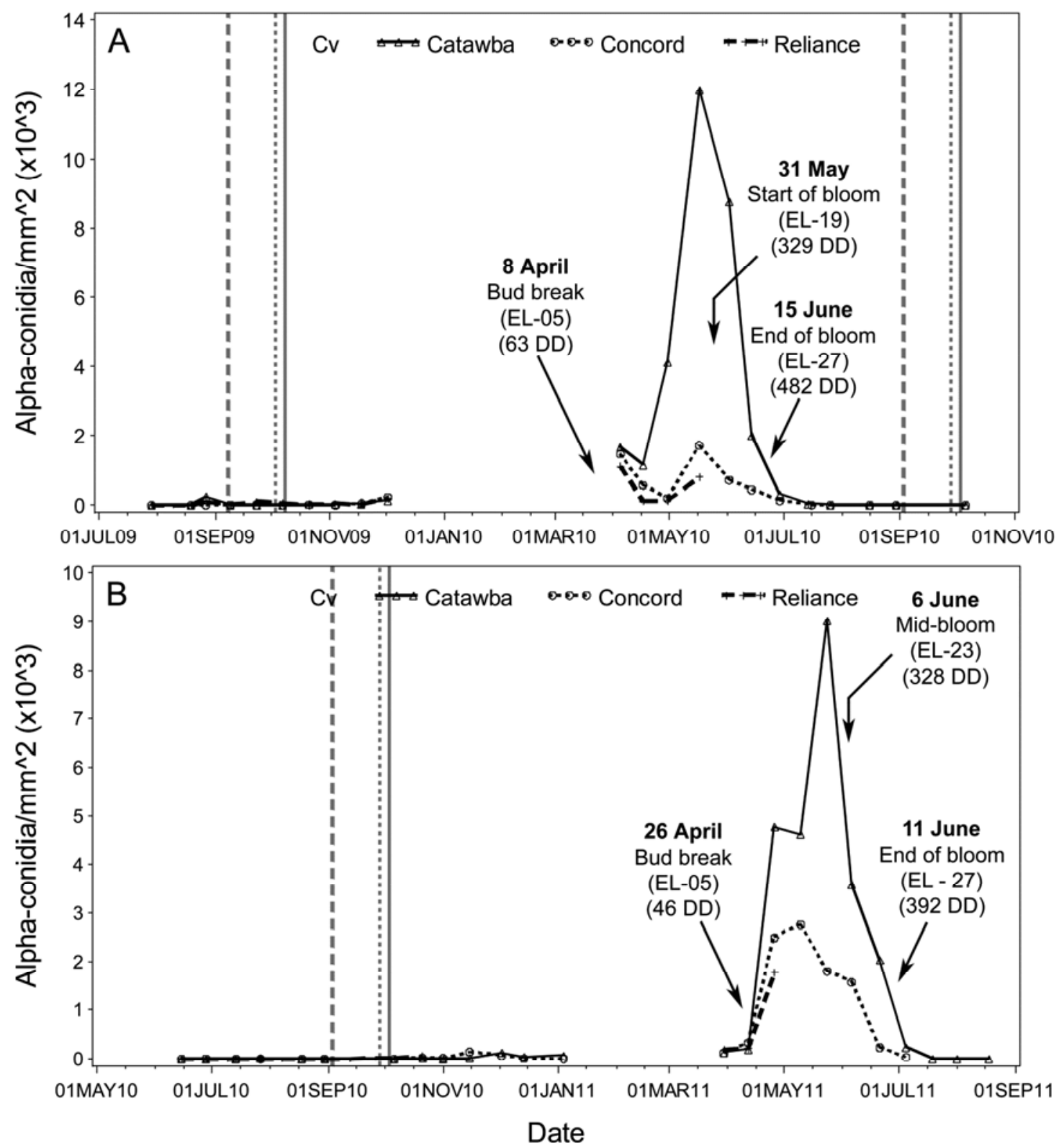

Fig. 2. Sporulation potential of Phomopsis viticola on grape rachises infected in A, 2009 and B, 2010. Reference lines are approximate harvest dates of the respective cultivars. $\mathrm{EL}=$ Eichhorn-Lorenz growth stage and $\mathrm{DD}=$ degree-days $\left(\right.$ base $\left.10^{\circ} \mathrm{C}\right)$ since $1 \mathrm{April}$. 
viability of conidia. $\beta$-conidia were sometimes observed to be produced along with $\alpha$-conidia in many cases but only $\alpha$-conidia were counted, because the role of $\beta$-conidia in pathogenicity of P. viticola is not clear $(16,18,21)$.

Relative sporulation potential. To determine whether there was a consistent trend in the sporulation potentials over time for each of the cultivar-tissue-year datasets, relative sporulation potential was examined. Relative sporulation potential was obtained by dividing sporulation potential at a given time by the maximum sporulation potential observed for the respective cultivar-tissue-year combination. Relative sporulation potential allows for the direct quantification of the temporal pattern of the sporulation capacity of the pathogen without the confounding effects of year and cultivar, and permits risk modeling of the time-of-year effects on the inherent capacity of the pathogen to produce conidia if environmental conditions are or become favorable. Relative measures of inoculum production have been reported under various names: relative sporulation (17), proportion of seasonal inoculum (3), and relative area under the spore production curve (20). This relative value is directly related to the risk probability of inoculum production.

Relative sporulation potentials for the entire dataset (all cultivartissue-year combinations) were plotted in relation to day of year (DOY), cumulative degree-days (beginning 1 April, with base temperature of $10^{\circ} \mathrm{C}$ ), and days since bud break. Data for Reliance rachises from both years was excluded from this analysis due to the small number of sampling points of those datasets. To determine whether all cultivar-tissue-year combinations could be pooled, a linear model was fitted to the relative sporulation potential data using the GLIMMIX procedure of SAS (version 9.2; SAS Institute Inc., Cary, NC). Nonlinear regression analysis was used to fit a modified $\beta$ model (1) to the relative sporulation data using the NLMIXED procedure of SAS. The modified $\beta$ model was of the form $y=\alpha t^{\beta}(1-t)^{\gamma}$, where $y=$ relative sporulation potential, $\alpha=$ relative sporulation potential (upper) asymptote, $\beta=$ rate of relative sporulation potential increase toward its optimum with increasing DOY, and $\gamma=$ rate of relative sporulation potential decrease away from its optimum with increasing DOY. Variable $t$ was equal to $(T$ $\left.-T_{\min }\right) /\left(T_{\max }-T_{\min }\right)$, where $T=\mathrm{DOY}, T_{\min }=$ minimum DOY of relative sporulation potential (first day with observed spores), and $T_{\max }=$ maximum DOY of relative sporulation potential (day after which no spores were observed). The same $\beta$ model was used for degree-days and days since bud break as predictor variables (with $T$, and so on, representing degree-days or days since bud break). Model appropriateness and goodness of fit to the data were assessed using residuals, correlation coefficient $(r)$, Akaike's information criterion (AIC), and concordance correlation coefficient $\left(\rho_{C}\right)(12,13)$.

\section{Results}

Sporulation potential of infected shoots and canes. Essentially no sporulation potential (less than $100 \alpha$-conidia/mm $/ \mathrm{m}^{2}$ ) was observed on shoots produced and infected during the 2009 growing season prior to harvest or during the dormant season. Exceptions occurred on 30 November 2009 and 27 March 2010 (both long after harvest), where Catawba and Reliance canes, respectively, were observed to have low (100 to $250 \alpha$-conidia $/ \mathrm{mm}^{2}$ ) levels of sporulation potential. Bud break (EL-05) occurred in the Catawba, Concord, and Reliance vineyards on 8 April 2010. Appreciable levels of sporulation potential were first observed on canes infected in 2009 on 12 April 2010 (Fig. 1). For Catawba and Reliance canes, sporulation potential peaked on 25 May 2010, which was shortly before the start of bloom (31 May 2010, EL-19) for all three varieties. Sporulation potential of Concord canes peaked on 26 April 2010. After reaching its peak, sporulation potential was generally observed to decrease rapidly. Bloom for all three vineyards ended (EL-27) on 15 June 2010, and essentially no sporulation potential of canes was observed after 6 July 2010. Sporulation potential was observed to be finished after 31 July 2010.

Results for sporulation potential of shoots and canes produced and infected in 2010 were similar to those infected in 2009. Essen- tially no sporulation potential was observed on current-seasoninfected tissues during the 2010 growing season prior to harvest or during the dormant season (Fig. 1). Appreciable sporulation potential was first observed on 18 April 2011. Sporulation potential of infected Concord canes peaked on 3 May 2011, shortly after which sporulation potential of Catawba and Reliance canes peaked on 15 May 2011. After 11 July 2011, sporulation potential of all three cultivars was observed to be depleted. P. viticola was always isolated from vortexed conidial suspensions from canes infected in 2009 and 2010.

Sporulation potential of infected rachises. Generally, no sporulation potential was observed on rachises produced and infected during the 2009 growing season prior to harvest or during the dormant season. Exceptions occurred on 27 August 2009 and 2 December 2009, where rachises of Catawba and all three cultivars, respectively, exhibited low levels of sporulation potential. Appreciable sporulation potential was not observed on rachises until the spring (5 April 2010) following infection (Fig. 2). In 2010, bud break (EL-05) occurred in the three vineyards on 8 April 2010. Shortly before the start of bloom (31 May 2010, EL-19), sporulation potential was observed to peak on 17 May 2010. Bloom ended (EL-27) on 15 June 2010, and essentially no sporulation potential of rachises was observed after 29 June 2010. Sporulation potential was depleted by 26 July 2010 .

No sporulation potential was observed on rachises produced and infected in 2010 throughout the 2010 growing season before harvest or during the dormant season. Exceptions occurred on 15 November 2010 and 2 December 2010, where Concord and Catawba rachises, respectively, were observed to have low levels of sporulation potential. Appreciable sporulation potential was first observed on 30 March 2011. Sporulation potential of infected Catawba and Concord rachises peaked on 24 and 10 May 2011, respectively, and no sporulation potential was observed after 5 July 2011. P. viticola was always isolated from vortexed conidial suspensions from rachises infected in 2009 and 2010.

Relative sporulation potential. A linear model fit to the combined relative sporulation data indicated that cultivar, tissue, and year factors did not significantly affect relative sporulation potential $(P=0.691,0.076$, and 0.909 , respectively). Thus, the modified $\beta$ model was used to predict relative sporulation potential for each time scale (DOY, degree-days, and days since bud break) over all cultivar-tissue-year datasets. Plots of residuals indicated that the modified $\beta$ model produced an appropriate fit to the relative sporulation potential data for each of the time scales (data not shown). The correlation $(r)$ of resulting predicted and observed relative sporulation potential was highest for DOY as the predictor variable (0.853), and it was lower for degree-days (0.806) and days since bud break (0.767) as the predictors (Fig. 3). The greatest variability in relative sporulation potential was observed when the data were plotted against days since bud break. AIC was lowest (i.e., best) for DOY as the predictor variable (AIC $=-55.1$ ), compared with $\mathrm{AIC}=-28.6$ for degree-days and $\mathrm{AIC}=-10.6$ for days since bud break. The concordance correlation coefficient was highest (i.e., best [upper limit of 1]) for the DOY predictor $\left(\rho_{C}=0.845\right)$ compared with $\rho_{C}=0.789$ for degree-days and $\rho_{C}=0.746$ for days since bud break.

Based on these goodness-of-fit results, relative sporulation potential was best predicted using DOY. Maximum relative sporulation potential was predicted to have occurred on 16 May (DOY $=136$ ), which was considered a fairly good approximation of the observed peaks in sporulation potential (Fig. 3). Parameter estimates for the modified $\beta$ model fitted to the DOY predictor variable were $T_{\min }=1$ March $(\mathrm{DOY}=60), T_{\max }=2$ August (DOY $=214), \alpha=6.185 \times 10^{5}, \beta=9.55$, and $\gamma=9.89$.

\section{Discussion}

This study represents the first report in which sporulation potential of $P$. viticola on infected grape shoots, canes, and rachises was quantified in relation to the production of primary and possible secondary inoculum. Reddick (19) had previously described PCLS 
as a monocyclic disease; however, he did not present data and only made general observations to support his statements. The production of secondary inoculum was not observed from infected shoots and rachises in the present studies; therefore, these results have provided evidence to support Reddick's early statement that PCLS is a monocyclic disease. Our studies also indicated that primary inoculum was mostly produced on infected canes and rachises during the season after infection, from about bud break until shortly after the end of bloom, at which time the capacity of the fungus to sporulate appeared to have ended. Results from these studies reinforce the importance of proper sanitation methods (i.e., pruning and removing as much diseased or dead tissue during the dormant season as is practical) to reduce sources of primary inoculum for the following growing season (9). Similarly, these studies also support the currently recommended use of fungicides for managing PCLS from bud break through bloom (2; W. Wilcox, personal communication). The present studies did not, however, examine sporulation potential of lesions on third-year or older tissues or on infected tissues that remained on the vineyard floor. Whether or not any difference in the temporal trend or level of sporulation potential exists for infected tissues remaining on the vineyard floor compared with those in the canopy, all dead grapevine canes and rachises should be removed from the ground during pruning.

Conditions used to induce sporulation in these studies were artificial (e.g., constant temperature and continual lighting) and do not represent the constantly changing conditions in the field. Thus, results from these studies are not intended to be interpreted as representing rates of actual sporulation occurring in the field. Instead, as previously mentioned, the sporulation potential of infected tissues at a given time in these studies represents the capacity of the fungus in those infected tissues to produce inoculum once in the presence of favorable environmental conditions in the field. Our approach was similar to that done for other systems $(10,20,22)$.

Sporulation potential of $P$. viticola from infected Catawba canes and rachises was generally found to be greater in magnitude than that from infected Concord or Reliance tissues. These studies, however, were not designed to determine the effect of cultivar on sporulation potential of infected tissues. Rather, our primary interest was on determining the effect of time since infection on relative ability of $P$. viticola to sporulate on different tissues. The observed difference in magnitude of sporulation potential could have been due to possible differences in microclimate and $P$. viticola population structure in the different vineyards or to the inoculation of the Catawba vineyard with $P$. viticola strain $\mathrm{OH}-22$.

It was interesting that, among the three time variables examined for predicting relative sporulation potential, the relationship was strongest for DOY (which is not based on crop phenology), compared with degree-days or days since bud break as the predictor variable. In contrast, previous studies with other pathosystems found strong relationships between measures of relative sporulation potential and degree-days $(3,20)$ or days after a physiologic event (20). Carisse and Lefebvre (3) also found that the relationship involving degree-days could be further improved by the incorporation of a dry-days threshold (i.e., time during which total rainfall below a specified amount resulted in no degree-day accumulation). We did not consider additional variables for predicting relative sporulation potential, such as dry-days, because of the reasonably strong effect of DOY, without a consideration of crop phenology or physiological time. The observation that bud break and bloom occurred at about the same time for all three cultivars helps to explain the lack of cultivar effect in predicting relative sporulation potential and accounts for the strong (simple) DOY effect in the nonlinear modeling. This result, coupled with the lack of year effect, provides some insight as to why the phenologically based time scales did not improve predictions of relative sporulation potential for PCLS in Ohio. Nevertheless, plots of relative sporulation potential versus degree-days and days since bud break remain effective in illustrating temporal dynamics of relative sporulation potential, and these plots also reinforce the observa- tions of sporulation potential of $P$. viticola on infected tissues being primarily from around bud break until shortly after the end of bloom.

The relationship between relative sporulation potential and DOY may be useful in future studies to scale predictions of actual sporulation of $P$. viticola according to DOY. For example, this could be applied if a model predicting sporulation was developed based on infected tissues at a fixed sporulation potential (equivalent to a fixed time since infection had occurred). Scaling of predictions appears feasible because of the consistent trend in sporulation potential over time for the different experimental conditions (year, cultivar, and tissue). The specific temporal pattern in relative sporulation potential of $P$. viticola in a given vineyard and year might vary somewhat (i.e., shift slightly from left to right, probably depending upon environmental factors) but the general trend in relative sporulation potential is plausible to be comparable.

Results from these studies also raise questions about how environmental conditions influence the duration over which infected
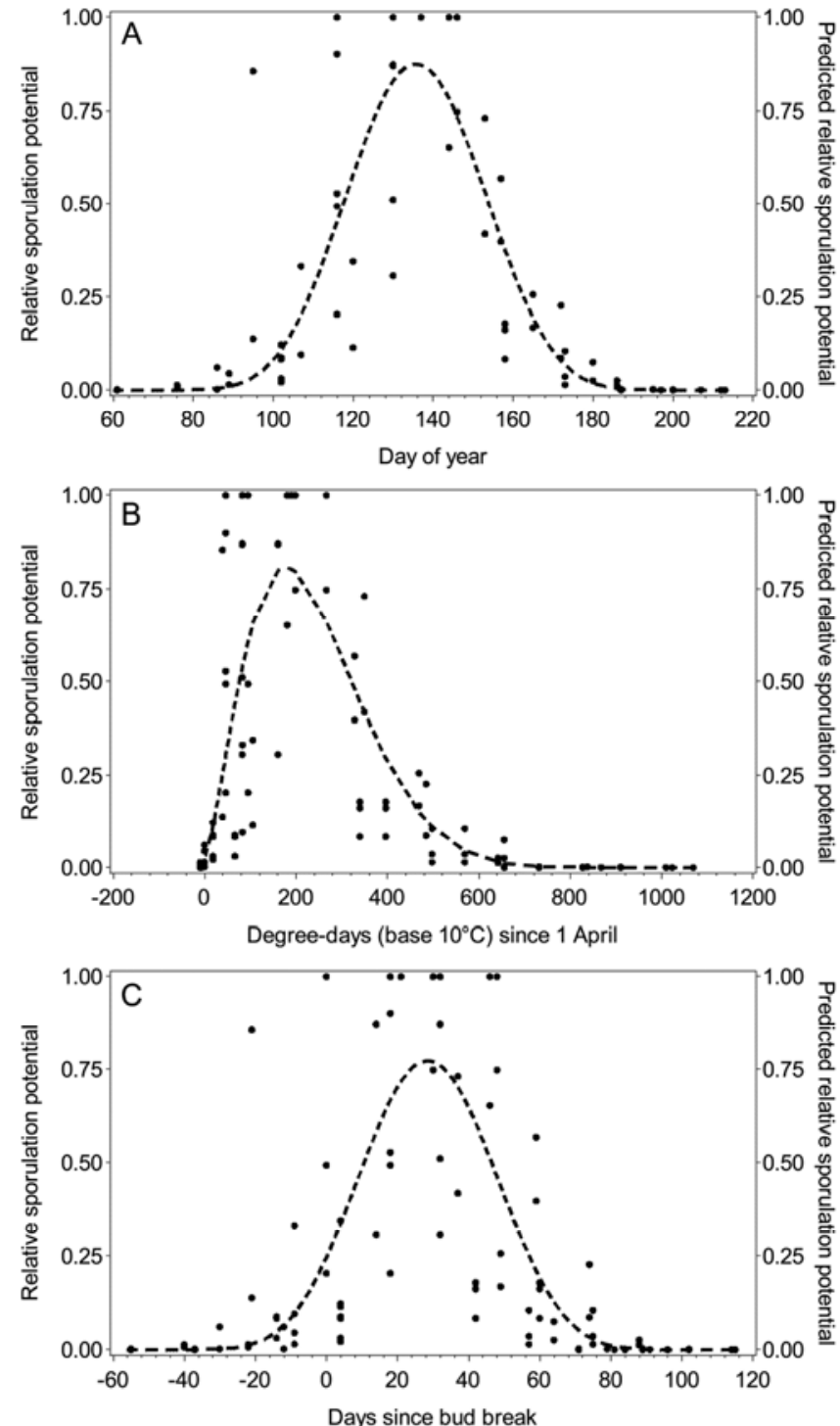

Fig. 3. Relative sporulation potential of Phomopsis viticola on infected canes and rachises of three varieties in repeated experiments ( 2 years) plotted against $\mathbf{A}$, day of year; $\mathbf{B}$, degree-days (base $10^{\circ} \mathrm{C}$ ) since $1 \mathrm{April}$; and $\mathbf{C}$, days since bud break. Day 60, 136, and 182 correspond to 1 March, 16 May, and 1 July, respectively. Plotted lines correspond to predicted relative sporulation potential according to a modified $\beta$ model. Correlation between the observed and predicted values $(r)=$ $0.853(\mathrm{~A}), 0.806(\mathrm{~B})$, and $0.767(\mathrm{C})$. Akaike's information criterion $=-55.1(\mathrm{~A}),-28.6$ $(B)$, and $-10.6(C)$. The concordance correlation coefficient $\left(\rho_{C}\right)=0.845(A), 0.789$ $(B)$, and $0.746(C)$. 
tissues are capable of sporulation. Future experiments could examine the relationship between the number and intensity of rain events and the duration and magnitude of infected tissues' sporulation potentials. Such a study could provide evidence as to whether or not the presence and amount of rain early in the growing season affects the time frame over which infected tissues are capable of sporulating and, consequently, the time frame in which growers should be protecting grapevines with fungicides.

\section{Acknowledgments}

Salaries and research support were provided by state and federal funds to the Ohio Agricultural Research and Development Center. Funding was also provided by the United States Department of Agriculture-Cooperative State Research, Education and Extension Service Viticulture Consortium-East Research Grants Program. We thank L. L. Wilson for his invaluable contributions.

\section{Literature Cited}

1. Analytis, S. 1977. Über die relation zwischen biologischer entwicklung und temperatur bei phytopathogenen pilzen. Phytopathol. Z. 90:64-76.

2. Bordelon, B., Ellis, M. A., and Welty, C. 2011. Midwest Small Fruit and Grape Spray Guide. Bulletin 506B2.

3. Carisse, O., and Lefebvre, A. 2011. A model to estimate the amount of primary inoculum of Elsinoë ampelina. Plant Dis. 95:1167-1171.

4. Cucuzza, J. D., and Sall, M. A. 1982. Phomopsis cane and leaf spot disease of grapevine: effects of chemical treatments on inoculum level, disease severity, and yield. Plant Dis. 66:794-797.

5. Dami, I., Bordelon, B., Ferree, D. C., Brown, M., Ellis, M. A., Williams, R. N., and Doohan, D. 2005. Midwest Grape Production Guide. Ohio State Univ. Ext. Bull. 919.

6. Eichhorn, K. W., and Lorenz, D. H. 1977. Phänologische Entwicklungsstadien der Rebe. Nachrichtenbl. Dtsch. Pflanzenschutzdienstes (Braunschweig) 29:119-120

7. Erincik, O., Madden, L. V., Ferree, D. C., and Ellis, M. A. 2001. Effect of growth stage on susceptibility of grape berry and rachis tissues to infection by Phomopsis viticola. Plant Dis. 85:517-520.

8. Erincik, O., Madden, L. V., Ferree, D. C., and Ellis, M. A. 2003. Temperature and wetness-duration requirements for grape leaf and cane infection by
Phomopsis viticola. Plant Dis. 87:832-840.

9. Hewitt, W. B., and Pearson, R. C. 1988. Pages 17-18 in: Compendium of Grape Diseases. R. C. Pearson and A. Goheen, eds. American Phytopathological Society, St. Paul, MN.

10. International Rice Research Institute. 1976. Climate and Rice. International Rice Research Institute, Los Baños, Philippines.

11. Jailloux, F., Bugaret, Y., and Froidefond, G. 1987. Inhibition of sporulation of Phomopsis viticola Sacc., cause of dead arm disease of vines, by fosetylAl under field conditions. Crop Prot. 6:148-152.

12. Lin, L. I.-K. 1989. A concordance correlation coefficient to evaluate reproducibility. Biometrics 45:255-268.

13. Madden, L. V., Hughes, G., and van den Bosch, F. 2007. The Study of Plant Disease Epidemics. American Phytopathological Society, St. Paul, MN.

14. Nita, M., Ellis, M. A., Wilson, L. L., and Madden, L. V. 2006. Effects of application of fungicide during the dormant period on Phomopsis cane and leaf spot of grape disease intensity and inoculum production. Plant Dis. 90:1195-1200.

15. Nita, M., Ellis, M. A., Wilson, L. L., and Madden, L. V. 2006. Evaluation of a disease warning system for Phomopsis cane and leaf spot of grape: a field study. Plant Dis. 90:1239-1246.

16. Pezet, R. 1974. Méthode favorisant la production de spores de type beta chez Phomopsis viticola Sacc. Phytopathol. Z. 79:67-76.

17. Pham, T. A., Miles, M. R., Frederick, R. D., Hill, C. B., and Hartman, G. L. 2009. Differential responses of resistant soybean entries to isolates of Phakopsora pachyrhizi. Plant Dis. 93:224-228.

18. Pine, T. S. 1958. Etiology of the dead-arm disease of grapevines. Phytopathology 48:192-196.

19. Reddick, D. 1914. Dead arm disease of grapes. N. Y. State Agric. Exp. Stn. Geneva N. Y. Bull. 389:463-490.

20. Scherm, H., Savelle, A. T., Boozer, R. T., and Foshee, W. G. 2008. Seasonal dynamics of conidial production potential of Fusicladium carpophilum on twig lesions in southeastern peach orchards. Plant Dis. 92:47-50.

21. Sergeeva, V., Nair, N. G., Barchia, I., Priest, M., and Spooner-Hart, R. 2003. Germination of $\beta$ conidia of Phomopsis viticola. Australas. Plant Pathol. 32:105-107.

22. Sutton, J. C., Liu, W., Huang, R., and Owen-Going, N. 2002. Ability of Clonostachys rosea to establish and suppress sporulation potential of Botrytis cinerea in deleafed stems of hydroponic greenhouse tomatoes. Biocontrol Sci. Technol. 12:413-425. 